\title{
Formação inicial de professores e projetos integradores do curso de Pedagogia: desafios e possibilidades
}

\section{Teachers' initial formation and integrative projects in pedagogy course: Challenges and possibilities}

Regina Lúcia Giffoni Luz de Brito é doutora em Educação: Currículo pela PUC-SP e mestre em Filosofia e História da Educação pela PUC-SP. Atua como professora e pesquisadora no Curso de PósGraduação em Educação: Currículo da PUC-SP. É membro do Comitê de Ética em Pesquisa da mesma instituição. Coordenadora do Grupo de Pesquisa credenciado pelo CNPq "Formação, atuação do educador e gestão educacional".

\section{Contato: luzdebrito@hotmail.com}

Marilice Pereira Ruiz do Amaral Mello é doutora em Educação: Currículo pela PUC-SP. Mestre em Gestão e Políticas Educacionais pela UNIMEP, Piracicaba, SP. Atua como coordenadora pedagógica e pesquisadora no Centro de Educação Especial do Estado de Alagoas Wandette Gomes de Castro nas áreas do Autismo, Altas Habilidades e Surdez. Faz parte do Grupo de Pesquisa credenciado pelo CNPq "Formação, atuação do educador e gestão educacional".

Contato: m.marmello@uol.com.br

\section{Resumo}

0 presente estudo parte do pressuposto que o currículo pensado para os Cursos de Pedagogia, mesmo depois das orientações das Diretrizes Curriculares Nacionais -DCNs, não contribui para a superação da fragmentação no processo de formação de professores. Verificou-se possibilidade de integração entre as disciplinas, por meio do componente curricular, Projetos Integradores e aprofundou-se análise sobre os Projetos Integradores do Curso de Pedagogia, da UFAL. Buscou-se refletir sobre a integração formativa de professores de Educação Infantil e anos iniciais do Ensino 
Fundamental; oferecer subsídios para a elaboração de Projetos Pedagógicos; contribuir para a ressignificação do currículo de formação de professores; evidenciar o modo como foram contempladas as diferentes dimensões dessa integração. Por meio deste estudo, os Projetos Integradores, enquanto umdos componentes do currículo do Curso de Pedagogia, mostrou-seintegrador e importante auxiliar em um necessário processo de desfragmentação do referido curso.

Palavras-chave: formação de professores; currículoeducação; Diretrizes Curriculares Nacionais; projetos integradores.

\begin{abstract}
This study assumes that the curriculum formulated for the Pedagogy Courses, even after the orientations of the National Curriculum Guidelines -NCG, does not contribute for the fragmentation overcoming in the process of teachers' formation. It was verified a possibility of integration between disciplines, by means of the curriculum component, Integrative Projects and deepening the analysis about the Integrative Projects of the Pedagogy course of the Federal University of Alagoas. It was reflected about the formative integration of Early Childhood Education and early years of elementary school teachers; it was intended to offer subsidiesto the elaboration of Pedagogical Projects; to contribute for the re-significationof teachers' education curriculum; to analyze from a practical perspective, how this integration was contemplated, in its different dimensions. Through this study, the Integrative Projects, asone of the Pedagogy Course component, proved to be integrator and important aid in a necessary defragmentation process of that course.

Keywords: teacher education; curriculum-education; National Curriculum Guidelines; integration projects.
\end{abstract}




\section{Introdução}

0 presente artigo é um recorte da tese de doutoramento (MELLO, 2013), advinda de uma trajetória pessoal e profissional de inquietações que surgiram ao longo desta caminhada, sobretudo as advindas do âmbito da Educação Superior. Ela teve o propósito de refletir sobre a implantação do novo Projeto Político Pedagógico Global (PPPG) do Curso de Pedagogia da Universidade Federal de Alagoas -(UFAL) no que se refere aos Projetos Integradores, investigando como estes são vivenciados pelos alunos, coordenadores e professores no dia a dia. Para tanto, o ponto de partida foi a consideração das Diretrizes Curriculares Nacionais - DCNs, do Curso de Pedagogia,estabelecidas na legislação educacional em vigor, normatizadoras e regulamentadoras da educação nacional, em especial, os instrumentos legais referentes à formação do professor para a Educação Básica.

Cabe ressaltar que os Projetos Integradores definem-se enquanto componentes curriculares capazes de proporcionar diálogo entre os diferentes núcleos de estudo, ao longo de toda a formação do pedagogo, sobretudo dos professores da Educação Infantil e anos iniciais do Ensino Fundamental.

Sendo assim, o estudo em questão tem a preocupação com a qualidade da formação de professores que trabalham ou irão trabalhar nesse nível de ensino, esperando contribuir para a melhoria da Educação, em especial, do estado de Alagoas, posto que é o estado com os mais baixos Índices de Desenvolvimento Humano (IDH), concentrando o maior número de analfabetos do país (UFAL. PDI, 2008-2012).

Tomando por base a literatura sobre a formação de professores, e os dados da realidade em estudo, faz-se premente uma formação diferenciada daquela oferecida pelos atuais cursos de Pedagogia, tendo em vista as peculiaridades do estado. É importante destacar que o cenário da pesquisa teve forte influência na escolha do tema, pelo fato de a UFAL contribuir, sobremaneira, para a formação dos profissionais do estado alagoano e ter grande responsabilidade social. 
Este é um momento propício para refletir sobre mudanças na dinâmica curricular, voltadas a uma ressignificação do currículo de formação do professor da Educação Infantil e anos inicias do Ensino Fundamental. Isto posto, ao delimitar o problema da pesquisa e a respectiva hipótese, busca-se contribuir para a formação de professores do curso de Pedagogia, de uma forma geral.

Apresentam-se aqui os resultados da pesquisa assim como "Subsídios para a integração formativa", com o fim de contribuir para as universidades que queiram trabalhar de forma integrada, como sugerem as DCNs. Destacam-se alguns pontos referenciais, a partir da pesquisa realizada, possibilitando a continuidade da reflexão que se faz sobre a formação inicial de professores para a Educação Infantil e anos iniciais do Ensino Fundamental.

\section{Resultados da pesquisa e subsídios para a integração formativa}

Ao definir o foco da pesquisa, identificar a existência de elementos inovadores em Projetos Integradores capazes de contribuir para a integração formativa dos professores de Educação Infantil e anos iniciais do Ensino Fundamental, por meio do Projeto Político Pedagógico Global do Curso de Pedagogia da UFAL, optamos por investigar os Projetos Integradores nos sete primeiros períodos do curso de Pedagogia, assim como os desafios e as possibilidades para a integração formativa dos professores, desde a concepção, planejamento e implantação do PPPG do Curso, compreendendo o período 2006 a 2011.

Em busca de respostas à questão formulada e aos objetivos elencados, optou-se por realizar uma pesquisa de campo, sob enfoque qualitativo, de cunho exploratório, complementada pela pesquisa bibliográfica e análise documental.

A pesquisa bibliográfica foi realizada por meio de consultas a diferentes publicações: livros, periódicos, artigos científicos, dissertações e teses. A análise documental pautou-se na consideração dos documentos legais, documentos da universidade, relatos das reuniões, encontro dos professores, e avaliação dos alunos, incluindo documentos relacionados ao Planejamento de Projetos Integradores.

As técnicas utilizadas na pesquisa de campo valeram-se de dois instrumentos de coleta de dados, o questionário e a entrevista com 
todos os sujeitos investigados. Para a análise dos dados utilizou-se da organização do material coletado e da análise de conteúdo, uma vez definidas as categorias.

Para a escolha dos sujeitos da pesquisa, buscamos alguns critérios importantes. Umdesses critérios diz respeitoàfamiliaridade com o tema em estudo, ou seja, sujeitos envolvidos com tal problema. Os sujeitos pesquisados totalizaram 34 (trinta e quatro), sendo: 2 (dois) coordenadores pedagógicos - o coordenador anterior, que participou ativamente da elaboração do PPP do curso pós-2006, e o atual, partícipes da implementação do referido projeto (ambos acumulam o cargo de professor); 3 (três) diretores do Centro de Educação, o atual, e outros dois que participaram do início da implantação da reforma curricular da Universidade em anos anteriores, e também acumulam o cargo de professor; 21 (vinte e um) professores e 8 (oito) alunos que estavam na Universidade de 2008 até 2012.

Considerando a diversidade de dados coletados nesta pesquisa, dispomo-nos a elencar algumas proposições relacionadas à integração formativa, assim como aos elementos que representam avanços,quando relacionados à ressignificação dos currículos de formação de professores, corroborados por pesquisadores como: Masetto (1997, 2000, 2004, 2010), Nóvoa (1991, 1992, 1995, 2009), entre outros.

Após entrevistar e analisar as entrevistas dos sujeitos, constatamos que o projeto do curso é tido como inovador pelos professores-autores do Projeto Pedagógico do Curso, sujeitos da pesquisa. Com isso, caminhamos em busca de identificaras características inovadoras, transformadoras, que apontam para a integração formativa e indicam de que forma favorecem a qualidade da formação de professores. Assim é que:

- o trabalho com os Projetos Integradores apresenta-se como inovador diante da proposta de articulação teoria e prática, desde o primeiro semestre do curso de pedagogia;

- a forma de trabalho apresentada por eixos temáticos é tida como uma inovação e parte da ideia de um trabalho por núcleos, já sinalizadas nas DCNs do curso de Pedagogia;

- a proposta de uma integração vertical e horizontal faz-se inovadora ao permitir que o aluno transite livremente, em busca de soluções de problemas. Tentativa esta, de romper com as barreiras das disciplinas. 
Masetto (2009) afirma que um currículo é inovador quando coloca o aluno

\begin{abstract}
[...] em contato com a realidade profissional desde o primeiro ano de faculdade, superando a exigência dos pré-requisitos teóricos, para se partir para a prática profissional. Trata-se de valorizar o espaço profissional como excelente ambiente para aprendizagem. Teoria e prática podem estar integradas facilitando a construção do conhecimento, planejadas de forma integrada, e com complexidade crescente, na medida que, a formação se desenvolve. Valoriza-se a integração das disciplinas básicas e clínicas ou profissionalizantes (MASETTO, 2009, p. 107).
\end{abstract}

Contudo, os desafios são muitos e partem do cotidiano do curso. Os desafios enfrentados com maior frequência pelos coordenadores, diretores de centro de educação, professores e alunos com o trabalho dos Projetos Integradores fazem-nos refletir sobre a real possibilidade de um trabalho voltado à integração formativa do aluno.

Diante desse contexto, nos itens que se seguem, tecemos algumas reflexões aliadas às propostas de enfrentamento dos desafios em direção às possibilidades sugeridas pelos entrevistados, autores referenciados e nossas, como pesquisadoras.

Pontuamos alguns itens que consideramos relevantes aos Projetos Integradores, como componente curricular. Assim, os Projetos Integradores precisam ser considerados:

- para além da integração teoria e prática;

- sob uma ótica ampliada para dessa forma, promover a integração do sujeito com o mundo;

- como referenciais a garantir uma visão de aprendizagem que pressupõe integração contínua de novos conhecimentos e experiências que resultem em aprofundamento do entendimento de nós mesmos e do mundo.

\title{
1.1 Transformando desafios em possibilidades
}

Elencamos aqui alguns desafios do cotidiano do curso que, se considerados, assinalam possibilidades em direção à efetivação de um currículo com características inovadoras que garantam a integração formativa. Para tanto, consideramos que 
[...] a escola [instituição de ensino], enquanto organização,é um sistema de relações e transações, lugar de encontros, de trocas; revela-se locus privilegiado para mudanças, posto que the é inerente o abrigo e o estudo, também, de contradições,complexidades, paradoxos, ambiguidades (BRITO, 2008, p.9).

Desta feita destacamos:

a) Trabalho individualizado em direção ao trabalho coletivo

Os professores, de forma geral, estão acostumados a trabalhar individualmente, e, mediante a proposição de um trabalho coletivo, enfrentam a resistência por compartilhar as ações que vêm realizando com seus alunos.

\footnotetext{
[...] a única saída possível é o investimento na construção de redes de trabalho colegiado que sejam o suporte de práticas de formação baseadas na partilha e no diálogo profissional. E mesmo as respostas sendo quase que unânimes com relação à necessidade de um trabalho coletivo, ele nem sempre acontece (NÓVOA, 2009, p. 22).
}

Além disso, a realização de planejamento coletivo e o diálogo, pensados no resgate do papel social da universidade, também contribuem para a qualidade do trabalho. Os entrevistados relataram que a dificuldade por trabalhar com os Projetos Integradores vincula-se ao fato de ser uma experiência muito nova e que vem apresentando vários desafios ao trabalho integrado. Dessa feita, ainda incipiente na cultura da escola, os Projetos Integradores sofrem as resistências advindas, não raro, da desinformação, do não saber fazer.

Os desafios relacionam-se ao trabalho individualizado do grupo de professores, do semestre e do curso como um todo. Como dito, a falta de integração vertical e horizontal,cristalizada na cultura da escola, favorece a fragmentação do saber.Concepção tendencialmente a ser ultrapassada, a partir do momento que o grupo, como um todo, acreditar que a aprendizagem deva ser compartilhada, solidária e cooperativa.

Sobre a questão da fragmentação, Pozo (2002) acrescenta também que os alunos devem ter uma concepção de coletividade para o aprendizado,

Frente aos tradicionais cenários nos quais a aprendizagem era uma atividade solitária, individual, em que cada aprendiz se achava sozinho diante da tarefa, sob o atento e inquisitivo olhar do implacável mestre, próprios também de uma cultura autoritária e sem solidariedade na 
apropriação do saber, a nova cultura da aprendizagem reclama também que a aprendizagem seja uma atividade social e não apenas um costume individual e particular. Fruto dessa tradição cultural ainda vigente, em muitas aulas e escolas continua predominando ainda a organização individual da aprendizagem, também chamada competitiva, já que nela o êxito de cada aluno é relativo ou depende do fracasso de seus colegas, se todos fazem mal seus erros serão menos penalizados. No entanto, há dados que avalizam a vantagem de uma organização cooperativa das atividades de aprendizagem, entendendo por isso as situações em que os objetivos que os participantes perseguem estão estreitamente vinculados entre si, de tal maneira que cada um deles pode alcançar seus objetivos se, e apenas se, os outros alcançam os seus (POZO, 2002, p. 257, grifos nossos).

Para esse outro aluno, há de se pensar um outro professor, fruto de outra formação integrada e integradora.

Vimos também que os projetos pessoais, arraigados na cultura da escola, superam os projetos de interesse da comunidade escolar e constituem-se em outro desafio, reforçado pela legislação, ao incentivar uma maior competitividade entre os professores quando elenca pontos para suas publicações e pesquisas.

A necessidade do envolvimento dos professores com pesquisas e publicações existe e Mizukami (2005-2006) aponta-nos que:

Os formadores devem estar envolvidos com o projeto político-pedagógico
do curso, construir parcerias com escolas e setores da comunidade,
trabalhar coletivamente e de forma integrada, elaborar documentação
a ser apresentada a órgãos oficiais, orientar trabalhos de conclusão de
curso, orientar pesquisa de iniciação científica, publicar regularmente etc.
Tais indicadores envolvem, igualmente (mesmo no caso de instituiçães
de ensino superior que não enfatizem a pesquisa acadêmica), condução
de pesquisa e regularidade de publicação (MIZUKAMI, 2005-2006, p. 152,
grifos nossos).

Assim sendo, não podemos nos prender aos interesses pessoais para realizar pesquisas, uma vez que estas têm a finalidade maior de contribuir para com a sociedade e resgatar a responsabilidade social da universidade e, por decorrência, o papel social da escola na formação de pessoas, profissionais críticos e criativos.

Na busca dos objetivos almejados, alguns obstáculos se interpõem, dentre eles a questão da carga horária.

b) Carga horária reduzida em direção à carga horária ideal

A carga horária representou em entrave a partir do momento 
que foram determinadas 40 horas para as atividades internas com o objetivo de se refletir sobre os elementos da prática pedagógica. Tomando por base os dados coletados, o que se propõe é uma concepção interdisciplinar, com carga horária mais elevada, que garanta também a realização de um estudo na escola campo de pesquisa, desde o primeiro período.

A reflexão sobre a extensão necessária para a carga horária seria de competência de cada instituição observando-se que nossa proposta requer o tempo suficiente para o aluno debater os casos encontrados na escola, no mesmo dia da observação. Prática inovada e inovadora que requer outras atenções, como as apontadas com relação ao quadro de professores.

c) Da mudança frequente do quadro de professores em direção à motivação e ao aumento do tempo de permanência na universidade

A mudança frequente do quadro de professores tornou mais difícil o planejamento coletivo,assim como a sua consecução,uma vez que, as questões inicialmente decididas pelo grupo,quando retomadas, de certa forma, retrocederam e/ou lentamente avançaram, tendo em vista tal rotatividade.

Os professores, por sua vez, afirmaram as dificuldades acima e acrescentaram outros desafios, como a desvalorização do trabalho e o acúmulo de atribuições proporcionalmente aos baixos salários. A pesquisa nos indicou,assim, que para um bom desempenho dos Projetos Integradores, é necessário comprometimento e um aumento de horas trabalhadas, dentro e fora da sala de aula. Dessa feita, evidenciou-se o número reduzido de escolas campo de estágio.

d) Quantidade reduzida de escolas campo de estágio em direção a um percentual suficiente e necessário

A quantidade de escolas campo de estágio foi, e ainda é, insuficiente para garantir o desenvolvimento de um bom trabalho de pesquisa de campo; muitos alunos em uma mesma escola e na mesma sala de aula redundaram em empobrecimento da visão crítica e criativa. 0 que se faz necessário é a criação de mais escolas campo de estágio e a divisão dos grupos de forma a diminuir o número de estagiários nas escolas parceiras da universidade. Exigência aliada a um necessário compromisso profissional.

e) Falta de compromisso em direção ao compromisso profissional 
Inicialmente vimos que a falta de compromisso dos professores nas falas, tanto dos alunos, como de diretores, coordenadores e dos próprios professores, aconteceu por não assumirem as horas das atividades com os Projetos Integradores. Os alunos disseram que os professores estavam desmotivados e ainda demonstram-se desmotivados. Nem sempre agem em direção ao que Masetto nos diz a respeito da responsabilidade do professor.

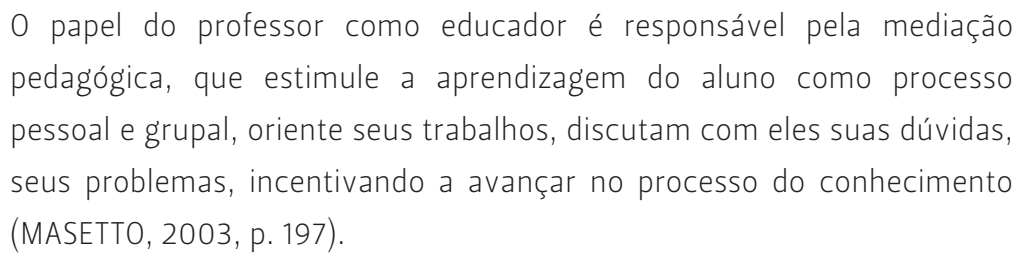

E, em relação aos professores que integravam o grupo, certamente as exigências são ainda maiores. Ao se eleger um professor-coordenador das atividades de Projetos Integradores, as atividades tiveram início, meio e fim. Porém, como nem sempre houve consenso na definição do professor-coordenador e nem todos os professores optaram por trabalhar com Projetos Integradores, uma vez que não há eleição e, sim, o aceite de um determinado professor para trabalhar com PI, sugerimos então, enquanto professores, a criação da figura do professor-tutor .

Apesar de esse encaminhamentonão ser consensual entre os entrevistados, alguns disseram que, quando os Projetos Integradores eram assumidos pelos grupos de professores, a integração nem sempre acontecia por não ter quem os assumisse, motivo de os alunos afirmarem de que se tratava de um projeto desintegrador. Mesmo diante de divergências, foi definido pelo colegiado do curso que um professor coordenaria os Projetos Integradores. Sendo assim, para os alunos ficou mais claro o começo, o meio e o fim dos Projetos Integradores. Com um planejamento bem definido, a execução das atividades aconteceu com melhor qualidade.

Percebemos também a existência de problemas relacionados à questão salarial. Tornou-se um grande impasse quando estabelecido o recebimento das horas-aula referentes aos Projetos Integradores. No início, quando todos os professores do semestre ganhavam as horas-aula, a integração acontecia, mais adiante, com o choque de horário, foram tiradas as horas de alguns professores, o que fez gerar novos problemas.

f) 0 dito em direção ao feito

Existe uma barreira entre o dito e o feito.0 currículo em ação, 
muitas vezes, não é aquele que foi planejado coletivamente. A grande ênfase do PPPG da UFAL está voltada ao eixo articulador, por meio dos Projetos Integradores, que é trabalhado desde o primeiro período do curso de Pedagogia.

Sacristán (1999) nos faz refletir sobre a ação, de forma a justificar essa incoerência entre o dito e o feito ao afirmar que,

\begin{abstract}
A ação refere-se aos sujeitos, embora, por extensão, possamos falar de ações coletivas, a prática é a cultura acumulada sobre as ações das quais aquela se nutre. Agimos a partir das ações, porque o fazemos a partir de uma cultura. A prática é a cristalização coletiva da experiência histórica das ações, é o resultado da consolidação de padrões de ação sedimentados em tradições e formas visíveis de desenvolver a atividade (SACRISTÁN, 1999, p. 73, grifos nossos).
\end{abstract}

Por estar incorporada àcultura da não reflexão sobre as ações, sobretudo as ações de um currículo integrador, direcionado a uma integração formativa, nem sempre o feito é o que está dito.

Aprofundando ainda mais as nossas proposições, sugerimos, por exemplo, que a partir de um tema geral proposto no semestre, seja eleito um tema específico para cada visita à escola campo de estágio. Os alunos observarão o que foi combinado previamente. 0 professor de Projetos Integradores do semestre fornecerá um texto direcionado ao assunto a ser discutido, após o término da observação, no mesmo dia. A reflexão feita dessa forma permitirá um maior aproveitamento e enriquecerá o conhecimento dos alunos.

Como técnica, sugere-se: dividir os alunos em grupo e, em forma de rodízio, os grupos irão mudando de escola, de modo que todos os alunos venham a conhecer mais de uma escola, em torno do mesmo assunto estudado.

Intenta-se mostrar os caminhos a serem seguidos para um maior sucesso dos Projetos Integradores, com vistas a garantir crescente qualidade do curso de formação de professores da UFAL e de outras universidades.

Propomos aqui um projeto-piloto na linha da integração formativa baseado nos estudos dos eixos integradores ou módulos. A ideia vem dos estudos de Nóvoa e Masetto, dos cursos de Medicina e Engenharia. Nos referidos cursos, os Projetos Integradores continuariam sendo o espaço para as discussões, porém, com algumas particularidades. 0 primeiro ponto a ser discutido é o professor coordenador dos Projetos Integradores, que 
passa a ser o responsável pela articulação, a integração entre os saberes de forma vertical e horizontal.

Complementamos nossa reflexão, elegendo como subsídios, as respostas mais frequentes dos entrevistados que se relacionam às categorias de análise encontradas. Sugerimos como subsídio um trabalho voltado a uma integração nas quatro dimensões: integração dos saberes, integração do currículo, integração do conhecimento, integração das disciplinas e o movimento entre elas, resultando na integração formativa.

Os Projetos Integradores favorecem os eixos articuladores para a composição de matriz curricular a partir do momento que:

i. articulam, integram conteúdos, conhecimentos, disciplinas, saberes e currículo:esse movimento pressupõe a integração formativa, a relação teoria e prática, a inovação do currículo e a formação de professores em torno daconcepção de Projetos Integradores.

ii. permitem superar a fragmentação por meio da integração: esse movimento pressupõe romper a barreira da disciplinarização, o que não significa romper com as disciplinas, mas com as paredes que as limitam; ressignificar teoria e prática; criar momentos coletivos em todas as licenciaturas; dialogar com a instituição de ensino e a sociedade; eleger um tema articulador, eixo temático; desenvolver e adotar postura voltada à interdisciplinaridade; desenvolver pesquisa e extensão usar tecnologias com a intenção de facilitar a integração vertical e horizontal, entre outros.

iii. permitem que a aprendizagem relacione-se ao ensino, pesquisa e extensão: sugerimos o desenvolvimento de uma aprendizagem centrada no aluno, com base na resolução de problemas como forma de ampliar sua capacidade de estabelecer relações entre os elementos estudados, assim como de considerar com mais criticidade os aspectos estudados.

Sugerimos ainda que os problemas partam das escolas campo de estágio; que os grupos de alunos da pedagogia sejam organizados da mesma forma que são atualmente, com a diferença, na realização de um rodízio entre as escolas no mesmo semestre letivo; que o tema seja definido pelo grupo, levando-se em conta o eixo articulador do semestre, no caso da Pedagogia, o módulo do semestre; que ao irem para as escolas, um professor-tutor seja indicado para acompanhá-los e, no mesmo dia, seja o responsável 
por promover debates sobre os casos-problema apresentados.

Acreditamos que os Projetos Integradores, como um componente curricular do núcleo integrador proposto pelas DCNs possa se tornar um dos propulsores para a integração formativa, em uma dimensão que vá além da integração teoria e prática,alcançando a própria formação pessoal e profissional do aluno docente e do próprio docente.

Como síntese das reflexões expostas neste estudo, esperamos contribuir para uma maior clareza da construção do movimento dos módulos que caracterizam a formação integrativa, tanto na perspectiva da integração vertical, quanto da integração horizontal.

\section{Considerações finais}

0 resultado da pesquisa ora apresentada representa exaustiva análise das condições sobre as quais os Projetos Integradores se tornam elementos inovadores e centrais na contribuição para a concretização da integração formativa dos professores de Educação Infantil e nos inicias do Ensino Fundamental.

Ao retomarmos o objetivo desta investigação, qual seja, identificar a existência de elementos inovadores em e para Projetos Integradores capazes de contribuir para a integração formativa dos professores de Educação Infantil e anos iniciais do Ensino Fundamental, por meio do PPP do Curso de Pedagogia da UFAL, constatamos que a realidade educacional, mesmo diante de suas contradições e impasses, permitiu-nos não só caracterizar tais elementos, como também destacar a importância destes no processo de construção da relação ensino-aprendizagem e da própria identidade docente.

Isso posto, caminhamos em direção à questão norteadora de nossa pesquisa, com o intuito de ratificar que os Projetos Integradores, enquanto um dos componentes curriculares, do Projeto Pedagógico do Curso de Pedagogia, da Universidade Federal de Alagoas, sugeridos pelas Diretrizes Curriculares Nacionais, trazem elementos capazes de contribuir para uma proposta curricular formativa inovadora, embutindo em sua constituição tanto possibilidades, quanto desafios, de diversas ordens para sua efetivação.

A partir dos questionamentos e reflexões manifestos nos aportes teóricos, assim como nos depoimentos dos sujeitos pesquisados, 
constata-se a importância do olhar inovador, da necessidade de se despojar das estruturas e de concepções que não mais dão conta, enquanto conjunto explicativo, de responder aos reclamos de "novos alunos" e de uma "nova realidade social e educacional", dinâmica, multifacetada e complexa.

Nesse sentido, os Projetos Integradores, quando construídos sob uma perspectiva de integração formativa e com a consideração de dimensões articuladas, contribuem efetivamente no processo de formação do aluno. Percebemos ao longo dessa caminhada de estudos e pesquisas o compromisso dos entrevistados por realizar um trabalho voltado à integração formativa, mesmo antes das DCNs. A necessidade de mudança acompanha os professores, e eles se unem em busca de soluções. Dessa feita, ocorre o que Brito (2008) sublinha quanto à garantia da qualidade da atuação dos professores. Para a autora, essa garantia prende-se também à criação de uma cultura que privilegia a articulação das complexas mediações que se estabelecem no processo de formação. Encontramos em Severino (2007) a confirmação dessa questão, ao afirmar que:

\footnotetext{
Quando se tem em pauta a condição profissional do educador, pode-se afirmar que só será garantida qualidade à sua atuação se, ao longo dos processos iniciais e continuados de sua formação the for assegurado, pelas mediações pedagógicas, um complexo articulado de elementos formativos, produzidos pelo cultivo de sua subjetividade, que traduzam competência epistêmica, técnica e científica, criatividade estética, sensibilidade ética e criticidade política. Será com uma prática guiada por referências dessa natureza que o profissional da educação poderá exercer sua função educativa no meio social, a partir de sua inserção num projeto educacional (SEVERINO, 2007, p. 131).
}

Observamos também que, apesar de serem relatados pelos entrevistados conflitos de ordem conceitual e de concepções sobre os Projetos Integradores, de forma geral, todos entendem que os objetivos do componente curricular passam por uma reestruturação e assumem as características de uma disciplina. Tal indicativo nos permite afirmar que o que parece de fato acontecer é uma verbalização indireta que intenta justificar o mau funcionamento dos Projetos Integradores, em alguns casos.

A forma como nasceram os Projetos Integradores destaca-se pela condição participativa, porém com a mudança do quadro de professores, aqueles que não participaram do processo sentiramse violados pelo direito de não terem opinado e, muitos deles, não tiveram tempo de se inteirar do processo, a ponto de se sentirem 
confiantes na sua viabilização prática, mesmo sendo uma proposta antiga de articular a teoria com a prática.

Destacamos aqui as possibilidades encontradas por meio dos elementos inovadores que contribuem para a integração formativa. É visível o entendimento do grupo sobre a importância do trabalho com os Projetos Integradores, de forma a promover a integração teoria e prática. Ao iniciar os trabalhos no primeiro período, os alunos mergulham na prática já nos primeiros dias de aula e, assim, com a ajuda dos professores, conseguem fazer a integração teoria e prática, por meio de discussões sobre os problemas das escolas e outros campos de atuação do pedagogo.

Apesar de o trabalho coletivo nem sempre acontecer, os alunos percebem a sintonia na fala dos professores e conseguem relacionar as diferentes disciplinas e encontrar uma possível solução para os problemas apresentados.

Mesmo diante de embates, considerando algumas declarações de que uma das prioridades da instituição pesquisada era a "racionalização"dos salários dos professores, o que acontece é que, de certa forma, ao trabalharem com os Projetos Integradores, os professores perceberam um caminho para a conquista da integração do currículo e, mesmo diante dos desafios, foram criadas alternativas para a concretização da integração, de modo inovador. 0 trabalho coletivo, partilhado, representa um dos elementos centrais, nesse processo, a favorecer a qualidade da formação de professores.

Retomando a nossa hipótese inicial de que os PPP dos Cursos de Pedagogia,quando elaborados sob um olhar inovador, no que se refere a uma perspectiva de integração formativa, considerando dimensões articuladas, contribuiriam para a formação do aluno, se confirma a partir do momento em que todos os sujeitos entrevistados buscam a integração em suas diferentes dimensões, com o fim de mais do que garantir a formação dos alunos, inovar o currículo de formação de professores. Com isso, os Projetos Integradores configuram-se em um componente curricular inovador e de fundamental importância na formação dos envolvidos no processo educacional.

Em Nóvoa (2007), buscamos a confirmação da importância de se investir e preparar professores para o despertar de sua motivação e de seu compromisso maior para com a sociedade, ainda mais em tempos de incertezas e de mudanças. 
umas a distância, outras menos, mas nada substitui um bom professor. Nada substitui o bom senso, a capacidade de incentivo e de motivação que só os bons professores conseguem despertar. Nada substitui o encontro humano, a importância do diálogo, a vontade de aprender que só os bons professores conseguem promover. É necessário que tenhamos professores reconhecidos e prestigiados, competentes, e que, sejam apoiados no seu trabalho, o apoio da aldeia toda. Isto é o apoio de toda sociedade. São esses professores que fazem a diferença. É necessário que eles sejam pessoas de corpo inteiro, que sejam profissionais de corpo inteiro, capazes de se mobilizarem. De mobilizarem seus colegas e mobilizarem a sociedade, apesar de todas as dificuldades (NÓVOA, 2007 p. 18).

Fica evidente, então, nos depoimentos dos sujeitos de pesquisa, assim como nas fontes teóricas e documentais coletadas, que 0 trabalho proposto com os Projetos Integradores constitui-se em vertente fundamental no processo constitutivo de cada professor. Uma formação voltada para além da integração teoria e prática, que pressupõe a inclusão de uma visão mais ampliada do fazer educativo e do papel social dos professores e da instituição, no compromisso de elevar qualitativamente a relação professoraluno e contribuir na formação de professores mais críticos, com base no diálogo e na abertura às mudanças, e, finalmente, aprofundados nas questões sociais, tão presentes no estado de Alagoas e em outras realidades deste nosso Brasil. Sabemos, entretanto, que passarmos do ideal sonhado para o real modificado exige o enfrentamento dos desafios que se oferecem na cultura das organizações educativas. 0 que exige, sem dúvida, novas e inovadoras pesquisas e estudos.

\section{REFERÊNCIAS}

BRITO, R. L. G. L. Reorganização curricular: gestão, cultura e clima da escola. In: Reunião Anual da ANPED, 2008, Caxambu. (Anais). Disponível em <http://www.anped.org. $\mathrm{br/reunioes/31ra/1trabalho/GT12-4893--Int.pdf>Acesso} \mathrm{em:}$ maio 2012.

MASETTO, M. T. Competência pedagógica do professor universitário. São Paulo: Summus, 2003. 
MASETTO, M. T. Aula na universidade. In: CUNHA, M.I.; SOARES, S.R.; RIBEIRO, M. Docência universitária: profissionalização e práticas educativas. Bauru: Editora UEFS, 2009.

MELLO, M. P.R.A. Formação inicial de professores e projetos integradores do curso de Pedagogia: desafios e possibilidades. 2013. 216 f. Tese (Doutorado em Educação: Currículo) - Pontifícia Universidade Católica de São Paulo, São Paulo, 2013. Instituição Financiadora: CNPq.

MIZUKAMI, M. da G. N. Aprendizagem da docência: professores formadores. Revista E-Curriculum, São Paulo, v. 1, n.1, dez.jul. 2005-2006. Disponível em: <www.pucsp.br/ ecurriculum>. Acesso em: agosto 2012.

NóvoA, A. Professores: imagens do futuro presente. Lisboa: Educa, 2009.

NóvoA, A. Desafios do trabalho do professor no mundo contemporâneo. São Paulo: SINPRO, 2007. [Palestra].

POZO, J. I. Aprendizes e mestres. Porto Alegre: ArtMed, 2002.

SACRISTÁN, J. G. Poderes instáveis em educação. Tradução de Beatriz Afonso Neves. Porto Alegre: Artes Médicas Sul, 1999.

SEVERINO, A. J. Formação docente: conhecimento científico e saberes dos professores. Ariús, Campina Grande, v. 13, n. 2, p. 121-132, jul./dez.2007. Disponível em: <www.ch.ufcg.edu.

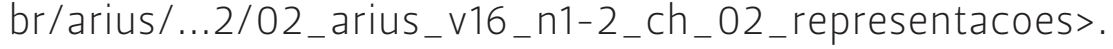
Acesso em: ago. 2013.

UFAL. UNIVERSIDADE FEDERAL DO ALAGOAS. Plano de Desenvolvimento Institucional2008-2012. Disponível em: <http://www.ufal.edu.br/>. Acesso em: out. 2012.

Recebido em: 24/02/2014

Revisto em: 08/04/2014

Aprovado em: 09/04/2014

www.veracruz.edu.br/ise

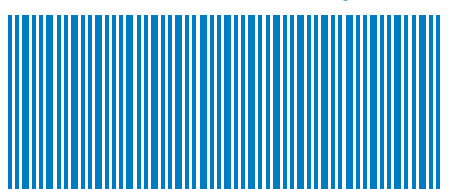

